\title{
Una infraestructura ramadera andalusí? Proposta d'adscripció cronològica dels aljubs de la Mola (Formentera, Illes Balears)
}

\author{
Antoni Ferrer Abárzuza \\ Universitat Autònoma de Barcelona \\ Antoni.Ferrer@uab.cat
}

\begin{abstract}
Resum. A la Mola, el promontori que ocupa l'est de l'illa de Formentera (Illa Balears) no hi havia més aigua que la de pluja. Hi ha nou aljubs que tenen anomenada de ser els més antics. Formentera va romandre despoblada des del segle XV fins al començament del segle XVIII. Els primers documents de la repoblació d'aquest darrer segle esmenten alguns d'aquells aljubs demostrant que ja existien aleshores. La instal·lació a començament de la segona meitat del segle XIII d'un convent de frares agustins a la Mola va generar una sèrie de documents que esmenten el bestiar que hi tenien els frares. Aquest article proposa la hipòtesi que aquells religiosos aprofitessin una infraestructura ramadera preexistent, andalusí. La situació dels aljubs és coherent amb la ubicació dels jaciments d'aquella època i amb la xarxa de camins tradicionals.
\end{abstract}

Paraules clau: Illes Balears, Formentera, la Mola, aljubs, cisternes, ramaderia andalusí.

\begin{abstract}
Resumen. En la Mola, el promontorio que ocupa el este de la isla de Formentera (Baleares) no había más agua que la de lluvia. Se encuentran nueve aljibes que tienen la fama de ser los más antiguos del lugar. Formentera permaneció despoblada desde el siglo XV hasta el comienzo del XVIII. Los primeros documentos de la repoblación de este último siglo mencionan algunos de aquellos aljibes demostrando que entonces ya existían. La instalación, al empezar la segunda mitad del siglo XIII, de un convento de frailes agustinos en la Mola generó una serie de documentos que mencionan el ganado que tenían los frailes. En este artículo se propone la hipótesis de que aquellos religiosos aprovecharon una infraestructura ganadera preexistente, andalusí. La situación de los aljibes es coherente con la ubicación de los yacimientos de aquella época y con la red tradicional de caminos.
\end{abstract}

Palabras clave: Illes Balears, Formentera, La Mola, aljibes, cisternas, ganadería andalusí.

\begin{abstract}
On the promontory called La Mola, at the East of the island of Formentera (Balearic Islands), there was no other water than the rainwater. There, we can find nine rainwater reservoirs commonly known for being the oldest of the place. In Catalan, these water reservoirs are called using an arabic origin word: "aljubs", the same as in Spanish: "aljibes". Formentera remained uninhabited from the XVth century up to the beggining of XVIIIth century. The first documents of the repopulation dated on the XVIIIth century mention some of those "aljubs" showing its previous existence. The foundation, starting the second half of the 13th century, of an Agustinian monastery produced a documentary series in which the cattle that the monks had is mentioned. In this paper we propose the hypothesis that the clergy men took advantage of a preexisting livestock infrastructure, that is, an andalusian one. The placement of those "aljubs" matches with the places where the Islamic archeological sites are located and also with the traditional roads system too.
\end{abstract}

Keywords: Balearic Islands, Formentera, La Mola, rainwater reservoirs, cisterns, andalusian cattle raising.

\section{L'aigua de la Mola}

"A la Mola no hi ha pous!" Va exclamar una dona, formenterera de la Mola, quan li va ser demanat si hi havia algun pou a prop de casa seva. La fulminant contundència de la resposta quasi expressava generacions d'esforç en la consecució de l'aigua. I, efectivament, no n'hi ha de pous (Marí Cardona, 1983, p.131). Mentre a la part baixa de l'illa de Formentera, una de les Balears, s'han inventariat setanta-quatre pous en un recompte que sabem incomplet, a la Mola, que és la part alta, no n'hi ha cap excepte, això sí, una sèrie de pouets situats vora mar, al peu dels espadats d'entre 80 i $120 \mathrm{~m}$ d'alçada que formen la costa de tota aquella zona. La dificultat per accedir a aquests pous costaners fa que, per ara, no els tinguem en compte. La Mola és la part oriental de l'illa de Formentera, té una extensió de $17,5 \mathrm{~km}^{2}$ (el total de l'illa és de $83,2 \mathrm{~km}^{2}$ ) i consisteix en un pla que se situa entre 75 i $140 \mathrm{~m}$ snm, amb un màxim de 195 
$\mathrm{m}$ a sa Talaiassa (Figura 1). Està rodat de penya-segats per tots els vents excepte l'istme d'1,6 $\mathrm{km}$ que l'uneix a la resta de l'illa: "a l'est de l'illa ens trobam amb un extens altiplà estructural d'uns $150 \mathrm{~m}$ d'altitud mitjana, clarament individualitzat per elevats penya-segats i un trencament brusc de pendent a la part de l'istme. Responent a la seua forma, és denominada la Mola" (Vilà Valentí, 1985). La part central de l'altiplà està ocupada per llims calcificats amb graves, l'envolta un cinturó de crosta calcària també del quaternari i els espadats estan formats per calcarenites del miocè superior (Guasch Ribas, 2006).

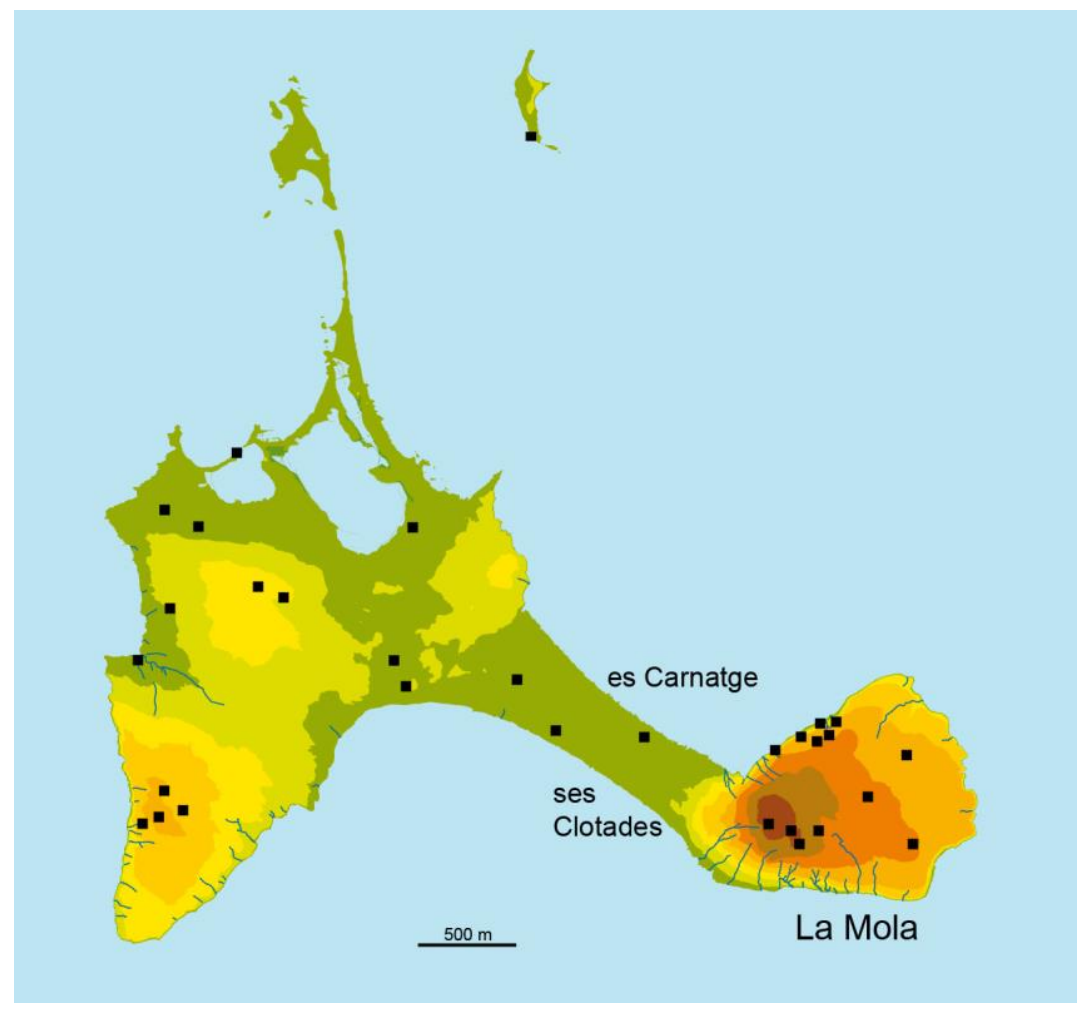

Fig. 1. Mapa de Formentera amb els jaciments d'època andalusí localitzats en les prospeccions de 1989-1990 (Dades del Programa de preservació de jaciments arqueologics de les Illes Pitiüses, coordinat per E. Díes Cusí. Mapa base: Enciclopèdia d'Eivissa i Formentera).

No hi ha pous a la Mola però existeixen, en canvi, almenys setze aljubs per a l'abeurada dels ramats. Després, cada casa té una o més cisternes i també deixarem ara de banda els cocons i bassetes naturals que a Formentera, com en altres indrets, s'aprofitaven per abeurar el bestiar mentre conservaven aigua de pluja. La pluja, per tant, ha estat històricament l'única proveïdora d'aigua a la gent i el bestiar de la Mola. La parla de Formentera distingeix bé entre aljubs i cisternes, els dos tipus existents de dipòsits per acumular aigua de pluja: els aljubs són rectangulars i coberts de volta, mentre que les cisternes, més fondes que amples, tenen planta circular i secció ovoïdal. "El destí d'aquesta aigua era tant el consum humà com l'abeurada del bestiar i, fins i tot, en alguns casos, el regatge de petits horts guanyats a l'esquerpa terra de l'illa" (Serra Rodríguez, 2006, p. 8). La paraula aljub prové de l'àrab al-jubb amb el significat d'“el pou". Les obres de Joan Marí Cardona $(1983,1994)$ tracten dels aljubs i cisternes amb molta atenció, així, després de recordar la inexistència d'aigües vives a la Mola, afirma que les primeres al·lusions en els papers són del començament del segle XVIII, quan l'illa es repoblà després de romandre deshabitada des del segle XV. Així mateix cridà l'atenció sobre l'al·lusió directa que fa un document del segle XIII a un lloc d'abeurada situat en el lloc del Carnatge, a la part baixa de l'illa, prop de l'istme, que ell interpreta com el pou del Verro, al Caló (Marí Cardona, 1994, p. 20). El 1712 es fa referència a l'aljub de la Plaerança i a l'aljub d'en 
Geniscai entre les partions de la divisió de la Mola que Marc Ferrer, el protagonista de la repoblació de l'illa, va fer aquell any entre les seves filles Vicenta i Àngela (Marí Cardona, 1983, pp.133). Aquest aljub d'en Geniscai és rebatejat per J. Marí com d'en Genís Call, tot advertint que aquesta és la seva interpretació de la grafia original. El mencionat document de partició al·ludeix a la característica més notable d'aquest aljub: "aljub d'en Geniscai que té una savina damunt la volta" (Marí Cardona, 1983, p.106). El fet que el dit any 1712 aquells dos aljubs es prenguessin com a elements notables presos a manera de fites per establir la divisòria entre les dues grans parts de la Mola és indicadora de la seva antiguitat; també ho és que hi hagués crescut una savina, prova clara que l'aljub no s'havia construït feia poc. El 1748 Carles Tur Ferrer, àlies "Damià", fill d'Àngela Ferrer, va establir unes terres de la Talaiassa de la Mola, a Antoni Maians fill de Bartomeu, un llaurador de Santa Eulàlia, a Eivissa, lloc de procedència de bona part dels colons repobladors. En l'escriptura d'establiment es fa menció al dret que l'emfiteuta havia de tenir en l'aljub de Can Ric, que J. Marí identifica amb el d'en Xomeu Maians (Marí Cardona, 1983, pp.308-309). Un altre document esmenta la divisió d'una hisenda -can Bartomeu Blai- feta el 1789, entre les condicions a què se sotmetien les dues parts hi havia l'obligació de construir un aljub a la meitat segregada de la finca igual en tot al que hi havia a la finca matriu i a cost de les dues parts (Marí Cardona, 1983, pp.303304). Igualment Marí s'atura en els documents que ens permeten conèixer que l'aljub anomenat del Poble va ser construït el 1851.

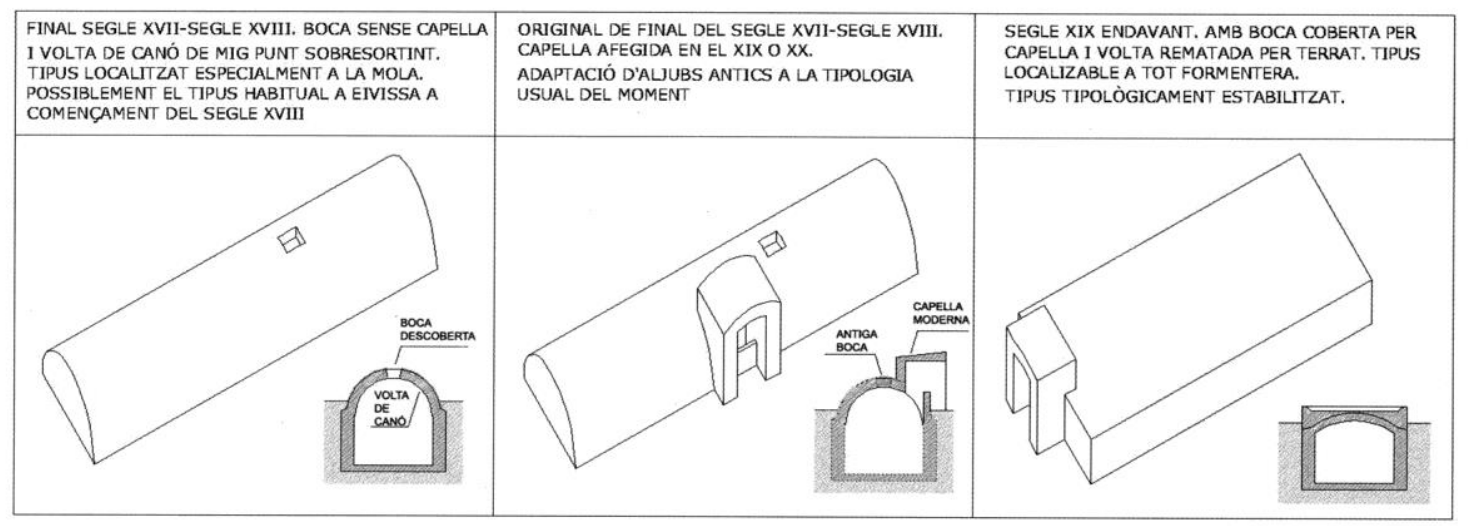

Fig. 2. Tipus bàsics d'aljubs de Formentera segons Serra Rodríguez (2006).

J.J. Serra, en el seu Inventari del patrimoni bidràulic de les Pitiüses (Serra Rodríguez, 2006, p. 143145) fa una descripció i classificació tipològica dels diferents aljubs i proposa una cronologia per a cada un dels tres tipus que en distingeix. El més antic dels tres és el que aquest investigador anomena "primitiu" (Figura 2). Correspon a aljubs documentats al començ del segle XVIII i que comparteixen una sèrie de característiques constructives: dipòsits rectangulars de poca amplada coberts amb volta de canó de mig punt, voltes fetes "de dues fulles de dovelles radials formades amb pedres de mida relativament gran, toscament escairades, recolzades sobre una clau o espinada formada per una filera de grans pedres planeres col·locades en aparell a plec de llibre, és a dir amb la junta situada a la cara major de la peça" (Figures 3 i 4). Aquests aljubs mostren sempre l'extradós de la volta, aixecada sobre el terreny circumdant, i la boca d'accés a l'aigua situada a l'espinada, prop d'un dels extrems o cap al centre (Serra Rodríguez, 2006, p.3 i p. 143) (Figura 5). Serra considera que els aljubs d'aquest tipus més primitiu són els més antics, com s'ha dit, i, concretament, en tractar de l'aljub Gran del Monestir, aventura que correspon a l'època de la repoblació iniciada el segle XVII “o potser a una data anterior" (Serra Rodríguez, 2006, p. 108) (Figura 6). J. Marí ja havia llançat la idea que els aljubs de la Mola podien ser "del temps dels ermitans de Sant Agustí o posteriors", és a dir del segle XIII en endavant (Marí Cardona, 1994, p. 20). Els aljubs que Serra agrupa en aquesta tipologia més antiga, afegint-hi alguns que ell no va veure, són nou: 
Taula 1: noms, dimensions i bibliografia dels aljubs de la Mola.

\begin{tabular}{|l|l|l|}
\hline \multicolumn{1}{|c|}{ Aljub } & $\begin{array}{l}\text { Dimensions } \\
\text { exteriors aprox. }\end{array}$ & \multicolumn{1}{|c|}{ Referències } \\
\hline Gran del Monestir & $7,70 \times 2,00 \mathrm{~m}$ & {$[25: 459 ; 27: 69 ; 33: 108-109]$} \\
\hline d'en Jaume Costa, abans dit d'en Geniscai, & $7,10 \times 2,50 \mathrm{~m}$ & {$[25: 459 ; 27: 71 ; 33: 102]$} \\
\hline d'en Pujada de sa Palmera & $9,50 \times 2,70 \mathrm{~m}$ & {$[27: 67 ; 33: 118-119]$} \\
\hline d'en Xiquet Baixero, antigament dit de la Plaerança & & {$[25: 459 ; 27: 54 ; 33: 122-123]$} \\
\hline $\begin{array}{l}\text { d'en Xomeu d'en Maians o d'en Roig, antigament dit } \\
\text { de Can Ric }\end{array}$ & $10,70 \times 3,00 \mathrm{~m}$ & $\begin{array}{l}{[25: 459 ; 27: 140 ; 33: 126-} \\
127]\end{array}$ \\
\hline d'en Rita & - & {$[25: 459 ; 27: 204 ; 33: 96-97]^{1}$} \\
\hline d'en Xomeu Sord & $10,80 \times 2,50 \mathrm{~m}$ & - \\
\hline d'en Tonet & $9,00 \times 2,80 \mathrm{~m}$ & - \\
\hline de Can Simonet & $6,80 \times 2,30 \mathrm{~m}$ & - \\
\hline
\end{tabular}


Figs. 3 i 4. Detall de l'extradós de les voltes dels aljubs de Can Xomeu Maians i de Can Xomeu Sord (Fotos: A. Ferrer).

1 Respecte de la inscripció àrab que tenia entre les pedres de la seva fàbrica: Maña de Angulo (1953). 


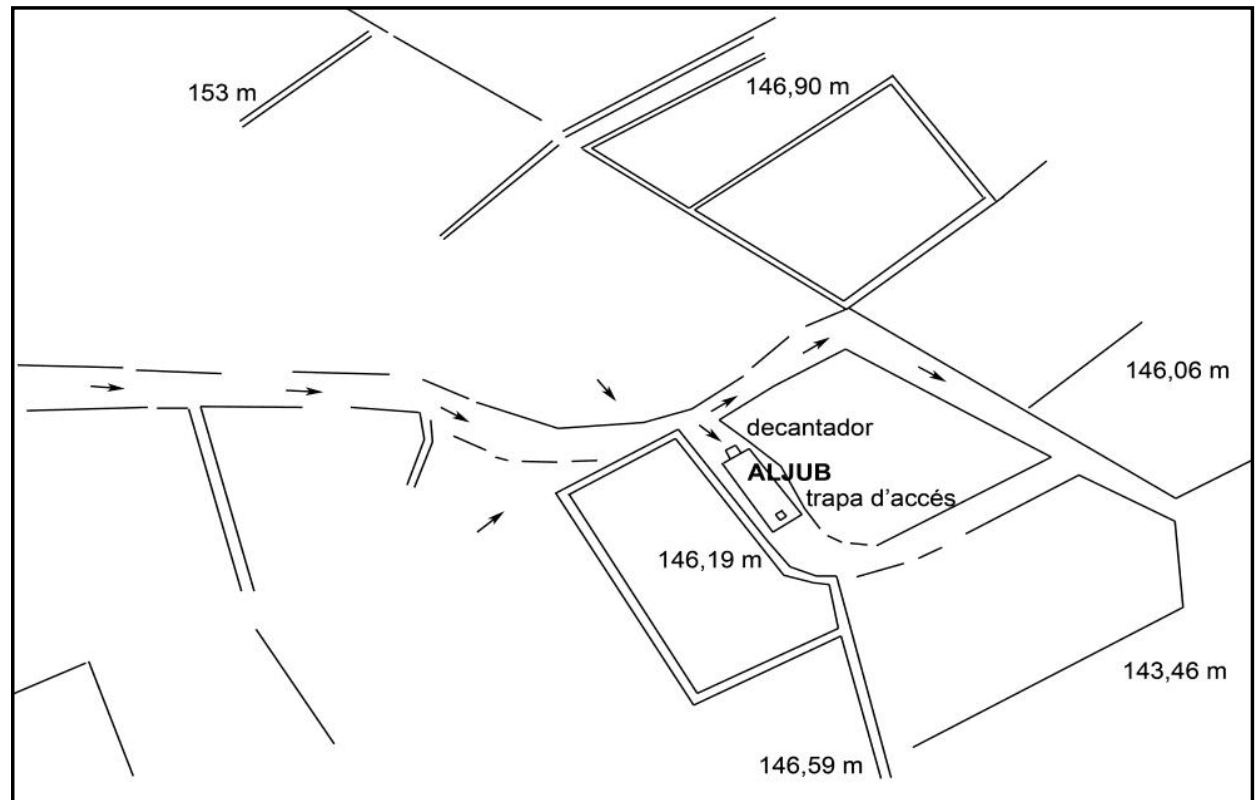

Fig. 5. Fotografia de l'aljub de Can Xomeu Maians (Foto: A. Ferrer).

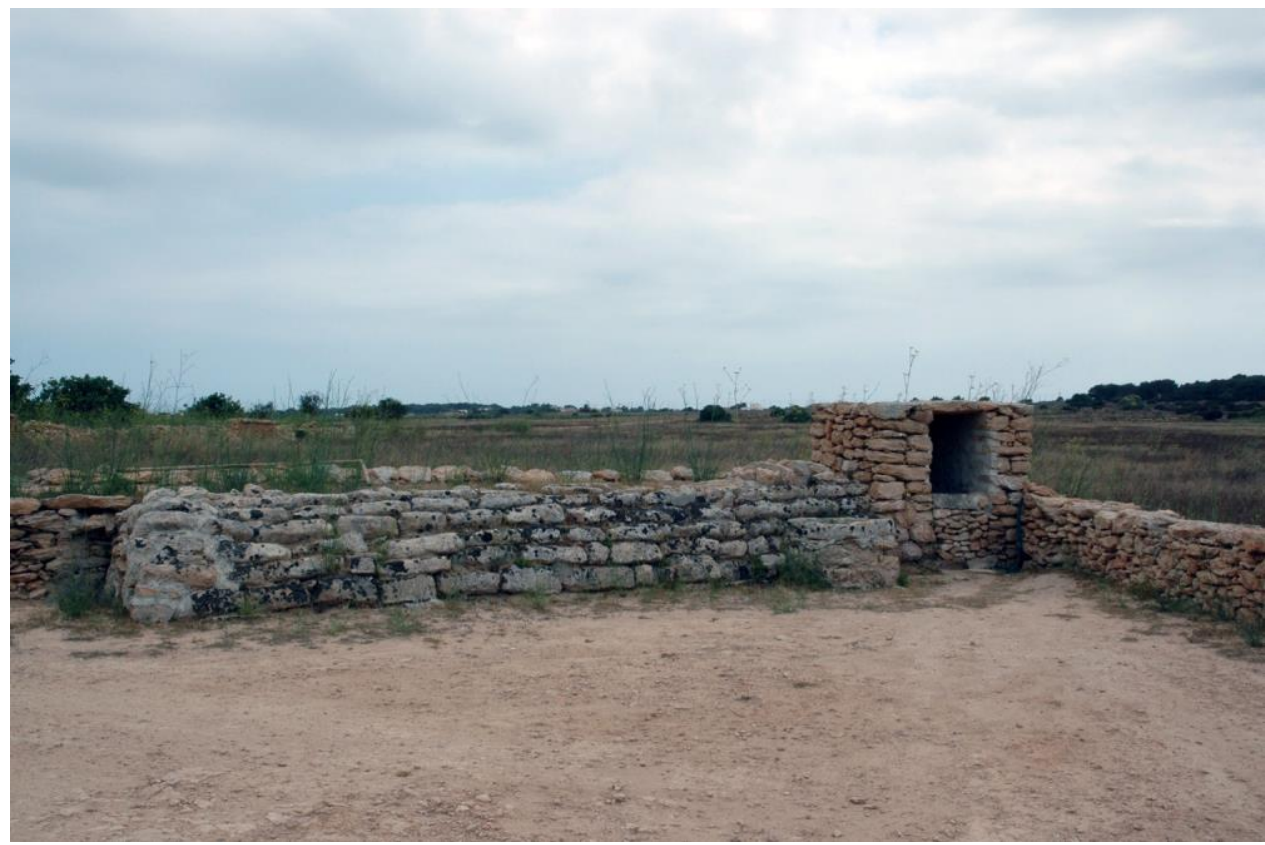

Fig. 6. Fotografia de l'aljub Gran des Monestir (Foto: A. Ferrer).

Es coneixen paral·lels d'aquest tipus d'aljub que han estat estudiats en quant a morfologia, distribució, funcionalitat i cronologia. Els més estudiats són els aljubs o cisternes situats a castells o busun estudiats per A. Bazzana (1992, pp. 251-257), però també n'hi ha d'abeurada, documentats sobretot a Almeria (Sánchez Sedano, 1988) i a altres zones ben delimitades del sud-est peninsular, indrets de característiques pluviomètriques i d'absència d'aigua subterrània comparables a Formentera (370-400 mm anuals). L. Cara Barrionuevo i J. M. Rodríguez han explicat la presència d'aquells aljubs rurals com a elements fonamentals d'una xarxa de rutes de transhumància ramadera que daten entre el segle XII i el XIII i que és coherent amb la ubicació dels aljubs (Cara y Rodríguez, 1989, p. 645). Els aljubs d'abeurada d'Almeria són de diferents grandàries però responen a un tipus morfològic molt semblant als de Formentera: 
"como forma constructiva presentan los aljibes elementos comunes: un embalse o depósito, generalmente rectangular y subterráneo, una bóveda de medio cañón que le cubre y una entrada de agua. Una puerta extrema de acceso al interior. La balsa de decantación previa, permite la avenida de agua depurada, mientras que la limpieza y encalado anual, antes de las primeras lluvias, asegura su conservación" (Cara y Rodríguez, 1989b, p. 44). Segons aquests autors, les dimensions dels aljubs tenen a veure amb el tipus de ramaderia que usa aquestes reserves d'aigua; així, les rutes transhumants necessiten d'aljubs grans, de bona capacitat (de més de $20 \mathrm{~m}$ de llarg), mentre que la ramaderia local origina aljubs més petits. A l'Alpujarra d'Almeria els aljubs són d'aquest tipus més reduït, amb dipòsits de 6 a $9 \mathrm{~m}$ de llarg per entre 2 i 3,5 m d'ample i "corresponden a una ganadería local y mediocomarcal" (Cara y Rodríguez, 1989b, p. 45). També a Múrcia es troben aquest tipus de dipòsits d'emmagatzemament d'aigua. Al municipi de Yecla, al nord-est de la regió, de $607 \mathrm{~km}^{2}$, el règim pluviomètric és d'uns $275 \mathrm{~mm}$ anuals. Un inventari dels aljubs d'aquella zona ha permès comptar-ne uns dos mil, dels quals només setze són dels anomenats "aljibes cimbrados", és a dir de volta, considerats d'origen medieval. Es tracta d'aljubs de planta rectangular amb coberta de falsa volta de canó de mig punt, feta per aproximació de filades. Les seves dimensions van dels 4 o $6 \mathrm{~m}$ de llarg fins als $16 \mathrm{~m}$, i n'hi ha un de $34 \mathrm{~m}$, però els més freqüents es troben entorn dels $10 \mathrm{~m}$. L'amplada oscil·la entre els $2,5 \mathrm{~m}$ i els $8 \mathrm{~m}$, essent la més repetida de $5 \mathrm{~m}$ (Ruíz y Azorín, 1989, pp. 612-621). Són, per tant, aljubs comparables als de la Mola de Formentera que ara tractem. Com era d'esperar, aquesta prospecció bibliogràfica en cap manera exhaustiva ens ha portat a trobar aljubs de volta de característiques semblants als de Formentera a indrets més propers, com l'illa de Mallorca i també uns pocs a Eivissa. En aquests llocs, com a Formentera, la seva relació amb la reproducció de bestiar està ben testimoniada, tot i que no en coneixem estudis específics.

Els aljubs del llistat formenterer han continuat en ús ramader fins al segle XX i alguns encara mantenen la seva funció. Altres han estat abandonats i la major part s'ha convertit en cisternes d'aigua per al servei de les cases properes, cosa que almenys en garanteix la conservació. Els aljubs que J.J. Serra inclou dins del seu segon model tipològic són abundosos i encara més les cisternes subterrànies de cos ovoïdal. Tots ells servien en els darrers temps per mantenir una cabanya ramadera de la qual coneixem les xifres per al conjunt de l'illa de Formentera. J. Marí, que tracta la qüestió, no proporciona xifres (Marí Cardona, 1994, p.127-132), però segons una dada de 1989 extreta del cens agrari de l'Institut Balear d'Estadística, aleshores s'hi comptaven 1.479 ovelles, 810 cabres i 293 porcs (Ferrer, 2006, p.85). Més endarrere en el temps, l'arxiduc Lluís Salvador d'Àustria proporciona dades rellevants i sistemàtiques referides a la totalitat de l'illa, sense que, com s'ha dit, es pugui discriminar la Mola de la resta del territori formenterer. Així, el 1867 hi havia 121 bous de tipus petit, de color roig groguenc, de banyes curtes i pèl llarg; les ovelles eren 2.240; les cabres 2.530, i els porcs 1.160. El 1885 el nombre de bous era de 133, el d'ovelles 3.226, el de cabres $2.592 \mathrm{i}$ el de porcs 1.072. Els ases, de color roig, eren 315 el 1867 i 313 el 1885; les mules eren 280 el 1867 (Marí Cardona, 1992, p. 213-214). La població de Formentera el 1860 era de 1.684 persones i de 2.258 el 1900 (Cirer Costa, 1986, p.13).

El 1666 s'assegurava que temps endarrere hi havia hagut bestiar a Formentera per a servei de la carnisseria d'Eivissa i que "per haver los corsaris y altres persones atalat i acabat lo bestiar que hi havia a penes hi ha per criar". És clar, i Marí se'n fa ressò, que el document tenia intencions ocultes respecte de l'illa de Formentera que anaven molt més enllà de fer-la servir de corral per a la veïna Eivissa i pretenia la seva cessió per part del rei. Deixant de banda això, queda clar que en aquell temps hi havia record del bestiar formenterer, aquell mateix any se n'hi dugué més i se'n fa esment els anys següents. El 1699 Francesc Llaudis va assegurar al rei que ell tenia uns corrals i unes casetes per als pastors que havia fet a l'illa de Formentera. Amb el bestiar que hi criava complia el contracte que havia fermat amb la Universitat d'Eivissa per proveir les carnisseries de la vila amb tres-cents anyells i ovelles 
anuals. Va ser un intent infructuós del dit Llaudis d'aturar la concessió reial de la mitja llegua quadrada a Marc Ferrer (Marí Cardona, 1983, p.33-37). És clar, per tant, que l'illa de Formentera, despoblada des del segle XV, va ser usada com a reservori del bestiar destinat als pilons dels carnissers de la vila d'Eivissa.

El segle XVIII, durant el procés de la repoblació de Formentera després del seu abandonament, els documents d'establiment de les terres als nous habitants proporcionen algunes dades sobre la gestió del bestiar (Marí Cardona, 1994, p.127-132). El 1705 l'escriptura d'establiment de dues parcel-les de terra a dos nous pobladors els permetia "pasturar a totes les terres emboscades" del domini directe de l'establidor; el 1712 un altre rebia autorització per dur les bèsties a les pastures comunes. Altres documents insisteixen en aquesta pràctica, així com en la importància dels cocons i basses naturals o condicionades del terreny on s'acumulava la pluja. És especialment important la consideració de les terres emboscades com a llocs de pastura. El 1676, poc després que l'ardiaca Bofí portés "una partida considerable de bestiar cabriu, de serda i llanar" a Formentera amb finalitat lucrativa (Marí Cardona, 1983, p. 34), Vicent Ferrer jutjà que el fracàs de l'intent de l'ardiaca havia estat causat per l'excés de bosc: el bestiar s'hi amagava i, sense estar encorralat, tornava salvatge i només es podia agafar caçant-lo, de manera que molta gent havia anat a capturar-ne per al seu propi ús. La solució que es considerava adient era desboscar, llaurar i sembrar diferents extensions de l'illa per fer-hi pasturar els animals (Marí Cardona, 1983, p. 36). Més tard, els il·lustrats del darrer quart del segle XVIII criticaren la manera de tenir el bestiar dels pagesos de l'illa: "Ya hemos dicho en la primera parte su débil estado y calidad por el abandono con que los mantienen lo más del tiempo, solos por los campos y en alguna estación seguidos por un muchacho de tierna edad, sin cuidar de su alimento ni bebida que tanto necesitan, ni si van por los montes o por los valles ni por último de las crías que producen". ${ }^{2}$ Les mesures que proposaven era tancar les heretats amb paret de pedra i fer pasturar els ramats en els rostolls per aprofitar els fems que dipositarien i tenir-hi corrals. Les informacions que aporten els il·lustrats sempre són en negatiu, és a dir, a partir del que afirmen que s'ha de fer, hom obté la manera com realment procedien els pagesos.

No hi ha, però, entre aquestes notícies del segle XVII, cap esment concret que permeti situar els llocs on es feia pasturar aquell bestiar. Cal recórrer a documents molt més antics, del segle XIII, per tenir-ne informació, i s'ha de dir que extraordinàriament abundosa per a un lloc tan petit.

\section{El bestiar dels frares}

L'illa de Formentera va quedar indivisa després de la conquesta de 1235 (Torres, 2005, p. 3335). Aquella indivisió territorial es va mantenir i el que es partien els seus senyors eren els fruits que produïen els habitants o explotadors quan n'hi hagué. El 1246 Guillem de Montgrí, sagristà de Girona i aleshores senyor de tres quartes parts indivises de l'illa, la donà en feu al cavaller Berenguer Renard amb la condició que la fes poblar (Aguiló, 1910-1911, p. 265-266; Marí Cardona, 1976, p.154-158). La infeudació enumera algunes excepcions molt interessants: l'alqueria "de Alchavito", que retenia Montgrí, i dos trossos a la Mola ("duobus spatiis soli in Mola"). Un dels dos "in quo possimus facere unum stallium cum trilia competenti ad opus nostri" ("en el qual puguem fer un estatge amb una era bona a servei nostre") i l'altre "alio solo in eadem Mola in quo Cacianus possit facere hospitium cum uno clauso pro farragenali et excepto uno orto ad opus dicti Caciani in alcheria de Arenal et excepto laboratione trium parium bovum in dicta Mola ad opus heremitarum cum vineis secundum pertinentiam dicte laborationis et in qua Mola dicto heremite possint facere oratorium et domos" ("un altre solar a la Mola on Cassà pugui fer una casa amb un tancat

2 AHE, Plan de mejoras. 
per farratge, i excepte un hort per al dit Cassà a l'alqueria de l'Arenal, i excepte un tros de la Mola tan gran com puguin llaurar tres parells de bous en un dia per al servei dels eremites, incloses en aquell sòl de conreu unes vinyes, i que en la Mola els dits eremites puguin fer un oratori i cases") (Aguiló, 1910-1911, p. 265-266; Marí Cardona, 1976, p.155). S'ha de fer parar atenció al fet que les reserves que fa Montgrí a la donació són per a coses que té en projecte, encara no construïdes o, almenys, els verbs que fa servir el sagristà de Girona així ho indiquen: per fer un estatge amb una era, per un hospici amb una tanca per a farratge $i$ perquè els eremites puguin fer un oratori i unes cases. Només l'esmentat hort de l'alqueria de l'Arenal sembla clar que ja hi era. El 1258 torna a esmentar-se aquesta zona d'hort.

Els eremites de 1246, doncs, encara no tenien casa ni oratori, tot i que és clar que existien i mostraven interès per l'illa de Formentera. Ara bé, d'ací a suposar, com fan B. Escandell (1994, pp. 227, 295) i F.X. Torres Peters (2014, p. 9) seguint Jayme Jordán (17, p. 46) que els frares hi eren des d'abans de la conquesta de 1235, hi ha molt i molt de camí. Es pot detectar, a més, una certa confusió entre el monestir de l'illa de Cabrera i aquest molt posterior de Formentera. Després, la situació d'aquells frares s'aclareix plenament sobretot amb documents editats per F.X. Torres (2005, p.42). L'11 de març 1257 el rei Jaume I va fer donació al nou orde de Sant Agustí dels seus drets sobre l'illa de Formentera, heretats el 1256 de Pere de Portugal Escandell (1994, p. 224) i consistents en una quarta indivisa de l'illa (Torelli da Bologna, 1675, pp. 45-46; Torres, 2004, pp. 103-104). Així queda clar que els eremites esmentats el 1246 pertanyien a una de les congregacions agrupades en el nou orde de Sant Agustí, creat pel papa Alexandre IV el 4 de maig de 1256 (Torres, 2014, p. 10).

El 3 de maig de 1258, Guillem de Montgrí, que apareix com a testimoni en el document reial de donació als agustins signat feia poc més d'un any, després de considerar que de 1246 ençà Berenguer Renard no havia acomplit els seus deures com a vassall, féu donació als dits frares de Sant Agustí d'una porció del seu dret sobre Formentera. Obrant de manera diferent al rei, Montgrí anà a pams i mentre aquell havia cedit tot el seu dret sobre l'illa, ell detallà ben bé què era l'objecte de la donació: "damus et offerimus... tres partes integras totius Mole insule de Formentaria cum arboribus et nemoribus et pascue, sicuti undique versant aque usque ad planum et hortum, sicut nos terminavimus presencialiter, qui est in alqueria que vocatur Arenal" ("us donem i oferim... tres parts íntegres de tota la Mola de Formentera amb arbres, boscos i pastures, i fins allà on les aigües vessen cap al pla, i l'hort que afitàrem personalment que hi ha a l'alqueria dita de l'Arenal") (Kirchner, 2002b, p. I, 276). Montgrí havia anat a Formentera -M. Sureda afirma "que degué viatjar a les Pitiüses quan li calgué" (Sureda, 2010, p.201)- i és clar que les fites de l'hort adjuntat a la donació de la Mola s'havien posat en la seva presència. Tant el rei com Montgrí prohibiren als frares alienar aquelles donacions i limitaren la seva validesa en tant que els agustins romanguessin a l'illa.

El cas és que el document de donació signat per Montgrí fa menció expressa que una de les activitats dels frares o dels seus vassalls era la reproducció de bestiar: "et quod possitis ducere vestrum bestiar ad adaquandum ad aquam que est in loco qui vocatur Carnatje" ("i que pogueu dur el vostre bestiar a abeurar a l'aigua que hi ha al lloc dit del Carnatge"). També és significatiu que la donació esmenti genèricament els arbres, els boscos i les pastures, i no digui res de terres conreades excepte l'hort del qual s'indica clarament que està situat cap al pla, és a dir a la part baixa, fora ja de la Mola. Es tracta del lloc de les Clotades, on tradicionalment s'hi ha fet hort gràcies a pous dotats de sénies que elevaven l'aigua cap a la superfície; actualment se'n conserven set. El lloc del Carnatge "comprenia tota l'ampla rada que va des de les costes espadades de la Mola fins a la punta Prima" (Marí Cardona, 1976, p. 164) i avui és una contrada més reduida, "tota la part septentrional de l'istme que uneix la Mola amb la part central de Formentera" (Ribes, 1996). El Monestir, per la seva banda, és el nom d'una vénda o comarca que ocupa la meitat nord de la Mola: "el Monestir, en la veu popular i en documents de propietat, és la comarca de gregal de la Mola, on algunes cases i hisendes 
també en mantenen el nom" (Marí Cardona, 1994, p. 20). Igualment, es conserva el nom de l'Arenal, esmentat en la donació a Berenguer Renard de 1246: "l'Arenal, avui reduï al lloc més oriental de la llarga platja de Migjorn, era aleshores una alqueria que amb tota seguretat comprenia una bona extensió de la llenca estreta de Formentera, limitant amb la Mola" (Marí Cardona, 1976, p. 164).

La donació feta per Montgrí als frares agustins va ser recorreguda pels hereus de Berenguer Renard en data desconeguda, posterior en tot cas a la mort d'aquest home escaiguda el 1261 (Torres, 2014). Montgrí va perdre el primer judici però va recórrer davant el papa i el 1272 obtingué una nova vista. Les actes ${ }^{3} \mathrm{~d}^{\prime}$ aquell segon enfrontament judicial contenen moltes dades d'interès sobre les activitats del monestir de Santa Maria de Formentera (Torres, en preparació). Entre els greuges que presentà la defensa de Montgrí per demostrar que la retirada del feu a Renard va ser legal, hi trobem que Berenguer Renard havia fet malbé l'illa i deixat que tornés erma i destruïda a causa dels porcs, truges $i$ altres bèsties seves $i$ d'altres que hi havia deixat anar. Esmenta concretament els porcs de Guillem de Montpalau. ${ }^{4}$ Aquest extrem es comprova perquè en el testament d'aquest cavaller datat a Vic el 1248 disposà dels porcs que tenia a Formentera i que cuidava un famulus -criat o servent- seu. En aquell document, Montpalau també llega allò que li devien Renard i el seu germà Arnau. ${ }^{5}$ Aquells animals, com va reconèixer el mateix Arnau Renard, van ser trets per ell de l'illa juntament amb les coses que tenia Berenguer. El judici va quedar sense sentència perquè a la mort Guillem de Montgrí els seus hereus -l'arquebisbat i el capítol de Tarragona- no continuaren la causa. Els principals beneficiats degueren ser els frares agustins ja que es prolongà el suspens de la primera sentència, contrària a Montgrí i que per tant afectava la donació que ell els havia fet el 1258 (Torres, 2005, p. 12).

Uns anys més tard, el 1298, es tornà a suscitar la qüestió de la validesa de l'anul·lació del feu de Renard i, per tant, de la donació als frares de Sant Agustí. Els hereus de Berenguer i Arnau Renard s'empararen de les possessions dels frares al-legant l'esmentada primera sentència. Tot el que succeí es va recollir en documents editats i comentats per F.X. Torres Peters en els treballs ja citats. El cas és que la comunitat d'agustins, reduïda aleshores a tres frares, protestà perquè els tres cavallers que es deien hereus dels Renard s'havien fet senyors "de bestiario dicte Mole et vestimentorum ecclesie et de omnibus mobilibus que in dicta domo sunt et omnibus mobilibus et per se moventibus dicte domus" ("del bestiar de la Mola i dels ornaments de l'església i de tots els mobles i semovents que hi havia de dita casa") (Torres, 2005, p.39). S'ha de fer notar que allò que primer s'esmenta en la descripció de l'abast de l'ocupació comesa contra els frares és el bestiar.

\section{E1 rastre construït dels ramaders andalusins}

És clar que la donació de les terres de la Mola als frares, vint-i-dos anys després de la conquesta, es féu amb la intenció d'incentivar el poblament d'aquella zona. Montgrí ja havia reconegut en la infeudació a Berenguer Renard de 1246 que la seva intenció era que Formentera es poblés. En un altre lloc hem insistit en les dificultats del procés colonitzador (Ferrer, 2008, p. 43). Respecte d'això, el 1248 Guillem de Montpalau encara no tenia clar que Eivissa i Formentera no quedessin despoblades o tornessin a mans dels sarraïns i en el seu testament va incloure una clàusula en aquest sentit: "volo quod si forte aliqua causa contingente

3 Es conserven a l'Arxiu Diocesà de Girona. F. X. Torres Peters, mentre prepara la seva publicació, ens ha proporcionat amablement la seva transcripció. Faig constar el nostre agraïment.

4 ADG, Processos medievals, núm. 1: "Item eo, quia dictus Berengarius Renard deterioravit et ad heremum dictam insulam non colendo ipsam ut promisit et etiam destruxit cum porcis et trugis et alio bestiario suo et alieno, scilicet recolligendo porcos et truias Guillermi de Montepalatio". Transcripció de F. X. Torres Peters, inèdita.

5 Arxiu Capitular de Vic, Cúria Fumada, testaments, I, f. 139v-140v. 
$x$ (ristia)ni amiterent insulam Evisse...". Així mateix, les treballoses condicions de la colonització quedaren reflectides amb inusual claredat a l'expedient judicial de 1272 abans utilitzat: "Item ponit quod eo tempore quo dominus sacrista dedit ad feudum dictam insulam dicto Berengario Renard et ipse possidebat illam regnum Valentie et Maioricarum cessabant esse populata et populabantur tunc, quod cedit quod maior pars regnorum Valentie et Maioricarum erat populata set non regna ad plenum nec sunt hodie" (Torres, en preparació) ("Demana si en el temps que el senyor sagristà donà en feu la dita illa l'esmentat Berenguer Renard i ell mateix [Arnau] la posseïen, el regne de València i de Mallorca estaven per poblar i, de fet, s'estaven poblant aleshores. Respon que efectivament la major part dels regnes de València i de Mallorca estava poblada però que no ho estan encara del tot avui dia”).

Com s'ha dit, el document de 1258 al·ludeix a una abeurada situada al Carnatge, prop del lloc abans justament anomenat caló de Sant Agustí i també caló dels Frares (Marí Cardona, 1994). És clar, però, que els animals havien de tenir llocs per beure a la part alta, on hi havia els "arbres, boscos i pastures" que esmenta el dit document de donació; d'altra manera, la ramaderia a la Mola no hauria estat possible. Cal fixar-se, a més, que aquella concessió ja preveu l'ús que farien els ermitans agustins -per ells mateixos o per mitjà dels pagesos que previsiblement hi portarien- de les seves noves terres: tenir-hi i reproduir-hi bestiar. Realment ho feren, tal com demostra el document ja al·ludit de 1298 quan animals, roba i mobles els foren arrabassats per uns cavallers. Fet i fet, tot indica que el 1258 la Mola era un lloc adient per a la ramaderia, però no ho era pas per les seves condicions naturals, més aviat adverses, sinó perquè es dedueix que necessàriament existia una infraestructura ramadera anterior, construïda pels andalusins, que la feien possible. M. Barceló i H. Kirchner dedueixen això mateix -l'existència d'una infraestructura andalusina-, dels esments a bestiar i llocs d'abeurada referits a la zona de Felanitx, Mallorca: "La ramaderia catalana seria, doncs, hereva dels ramats andalusins, molt importants en la formació dels assentaments que estudiem" (Barceló i Kirchner, 1995, p. 54). C. Batet demostra amb claredat, però tractant dels monjos cistercencs de Poblet i de la Real de Mallorca, la seva capacitat d'adaptació a les circumstàncies de les terres conquerides on s'instal laren (Batet, 204, p. 117). Doncs bé, els frares del nou orde de Sant Agustí fundadors del monestir de Santa Maria de Formentera, consideraren, a la vista d'allò construït que hi havia a la Mola, que la font de subsistència i eventual lucre més factible era la ramaderia. El 1246, quan la instal·lació dels eremites era un projecte o es trobava en un estat molt inicial -encara no tenien casa ni oratori-, res no se'n diu del bestiar, sinó de tres jovades de terra de llauró i d'una vinya. El 1258, després de la visita a Formentera de Montgrí, la cosa havia canviat i la donació es va fer amb coneixement real del territori i de les seves possibilitats. És aleshores quan s'esmenta el bestiar i el lloc on podia ser abeurat amb aigua de pou.

La dedicació ramadera dels andalusins de Faramantira (Formentera) queda testimoniada en el Liber Maiolichinus de Gestis Pisanorum Illustribus. El 1114, una avançada de l'estol de la Croada pisanocatalana tocà terra a Formentera: "Insula stat pelago (partes ea respicit Austri / adversum Libycos), cui Frumentaria nomen. / Hanc Latii petiere viri properanter, et illic / ceperunt victus placidae solacia praedae / perpinguesque boves, quibus et vesci potuissent / ni pia Christicolis probiberunt tempora carnes". / Lustrantesque locum, quo gens inamata latebat, / abstractos caveis Ebusum duxere ligatos." ("en medio del mar se yergue una isla (mira hacia la parte del Austro, frente a los Líbicos) cuyo nombre es Frumentaria. A ella se dirigieron veloces los hombres Lacios. En ella obtuvieron comida, botín plácido y reconfortante, e incluso unos corpulentos bueyes que también habrían podido comer si aquellas piadosas témporas no prohibiesen la carne. Inspeccionaron el lugar, que servía de refugio a gentes detestables, y sacándolos de las cuevas los llevaron atados a Ébuso”) (Castelló, 1996, pp.150-153). En concret, de fet, la menció que s'hi fa de les coves està assenyalant directament al lloc de la Mola, on les coves són

6 ACV, Cúria Fumada, testaments I, f. 139v a 140v. 
nombroses i algunes mostren rastres d'ús o freqüentació en temps andalusins. Concretament, H. Kirchner (2002, p. 208) situa els materials més antics recuperats en prospeccions de la Cova des Fum en els segle X i XI i l'ús o ocupació de la cova s'allarga fins al segle XIII. El poeta pisà fa esment dels bous per la seva inesperada presència i per destacar la pietat dels pisans, ja que, tenint-la a mercè, no menjaren tota aquella carn perquè era temps de quaresma. La resta del bestiar no mereixia atenció especial i queda englobada dins de la paraula botí (praedae). De les cabres, però referint-se a Eivissa, en va fer esment després alZuhrî (mort entre 1154 i 1161) per dir que s'hi donaven bé, molt millor que no les ovelles, que hi eren més rares (Barceló, 1984, p. 50). J. Ramon i M. Colomar han detectat arqueològicament restes d'ovicàprids en el jaciment de la Murada de la Cala, datat per aquests investigadors en el segle IX i abandonat no després del X. Aquesta constatació els porta a afirmar que "gairebé segur que eren pastors, vista la fauna, relativament abundant trobada en diferents estrats" (Ramon i Colomar, 2010, p.158).

L'ús ramader de la Mola queda testimoniat de manera encara escassa però suficient per al nostre objectiu en aquestes pàgines. Esperem que futures excavacions arqueològiques aportaran més restes òssies o d'altre tipus que n'ampliïn i enriqueixin l'evidència en quantitat i qualitat. L'especial característica de la Mola, de pràctica absència d'aigües subterrànies i el fet de ser un territori concret, delimitat i il·luminat, almenys tènuement, per la documentació relativa al monestir de Santa Maria, ha de permetre quantificacions d'altra manera impossibles o, almenys, més difícils d'obtenir: quantes bèsties podia mantenir la infraestructura ramadera de la Mola i quanta gent podia gestionar i subsistir amb aquells animals. Així mateix, del volum d'aigua disponible s'ha de poder inferir el sostre de població humana i animal de l'indret. Aquest volum és susceptible de ser conegut perquè, com s'ha dit, depèn exclusivament dels aljubs. J.J. Serra (2006) ha destriat, entre tots els aljubs i cisternes que ell coneixia a la Mola, un tipus que per la seva morfologia constructiva ha de correspondre -afirma- al primer moment de la repoblació del segle XVII o abans. També s'ha dit que J. Marí considerà que els aljubs més vells de la Mola havien de ser de temps dels frares agustins. Els aljubs que responen a les característiques descrites per Serra són nou i això significa, a falta de la planimetria de tots ells, no més de cent cinquanta mil litres d'aigua. És clar que la grandària dels aljubs té directa relació amb la seva superfície de captació i aquesta amb la quantitat de pluja anual. Quants litres consumeix cada exemplar de cada tipus d'animal en un dia de cada estació de l'any? Quant de temps se'ls pot deixar sense beure? I les persones? Afinant capacitats, pluviometria i les respostes a aquestes preguntes es podria fer una estimació ajustada de la cabanya ramadera que podia suportar la Mola almenys immediatament abans de la conquesta (Figura 7).

\section{Camins}

A més dels indispensables aljubs, una altra part important de la infraestructura ramadera andalusí de la Mola eren els camins. La coherència de la situació dels aljubs en la xarxa de camins és un criteri important en aquesta proposta que planteja que una sèrie d'aljubs de la Mola siguin d'origen andalusí i expliquin l'activitat dels habitants dels diferents assentaments localitzats a la zona gràcies a les prospeccions. Tornant al document de 1258, ja s'ha esmentat el dret dels frares a conduir els seus ramats a baix, al Carnatge, passant dels $150 \mathrm{~m}$ del pla de la Mola al nivell del mar. L'al•lusió a aquest dret dels frares és, en realitat la descripció d'un camí. És un camí que ha arribat a l'actualitat amb el nom de camí de la Pujada. Sense més anàlisi, per ara, que l'observació de la fotografia aèria de 1956 i el coneixement del territori, aquest camí té una primera desviació durant l'ascens. Aquest primer braç es desvia a l'E i arriba als aljubs d'en Tonet, d'en Xomeu Maians i, per últim, al de Can Rita. El camí principal s'esfilagarsa en tres braços quan assoleix la plataforma de la Mola. Anant de N a S, el primer braç es dirigeix cap a l'aljub d'en Xiquet Baixero, després 
passa pel de Can Simonet i finalment permet arribar al d'en Pujada de la Palmera. El braç central del camí arriba, travessant la vénda del Monestir, al lloc i aljub d'aquest mateix nom.

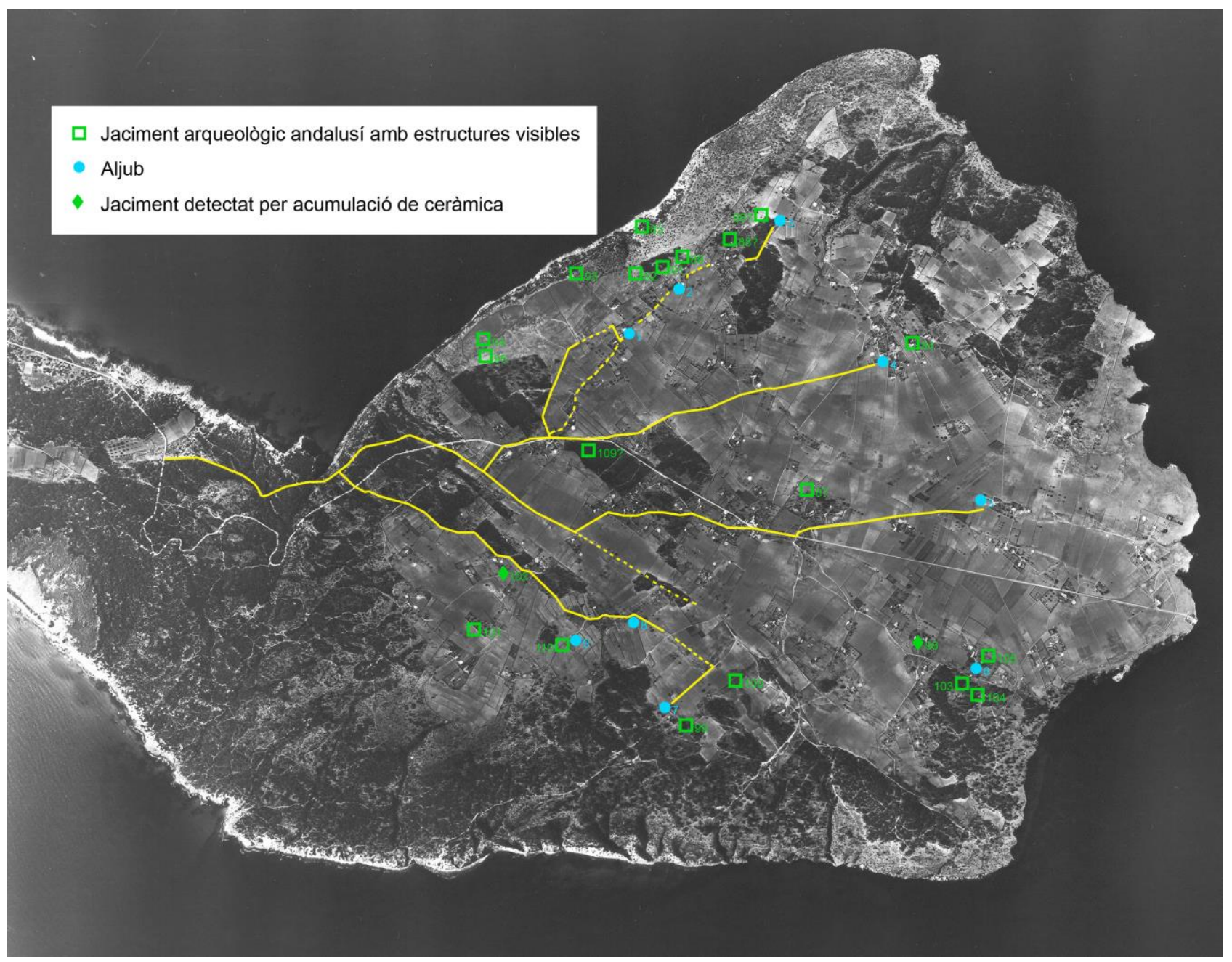

Figura 7. Foto aèria de la Mola, feta el 1956 per la Força Aèria d'USA, amb la situació dels jaciments arqueològics d'època andalusí, els aljubs i els camins tradicionals. La numeració dels jaciments correspon al número de fitxa en el Catàleg del Patrimoni cultural de Formentera. Font: Programa de preservació de jaciments arqueològics de les Illes Pitiüses.

El tercer braç de la forca arriba per terres de la vénda de la Talaiassa fins a l'aljub d'en Jaume Costa, situat dins la vénda del Monestir. Aquests dos camins no passen pel centre del pla, on es troba el poble de la Mola, agrupació de cases al voltant de l'església construïda al final del segle XVIII. Un dels cinc camins radials que neixen o moren en aquest poblet arriba a l'aljub d'en Xomeu Sord, que també es pot trobar des del camí esmentat de la Talaiassa. A l'actualitat alguns d'aquests camins estan perfectament clars i en ús, com el camí del Monestir i el de la Talaiassa, d'altres, els dels extrems laterals són més difícils de seguir. La foto aèria de 1956 mostra més restes que no les conservades actualment.

Observats amb detall, resulta que els aljubs recullen aigua dels camins que passen vora ells (aljub d'en Xomeu Maians, d'en Xomeu Sord), de les eres associades a les cases vora les quals se situen (d'en Jaume Costa, d'en Simonet, del Monestir) o dels pendents favorables del terreny (aljub d'en Tonet, d'en Rita). Això, però és la seva situació actual, el fet que estiguin a tocar dels camins pot indicar que es conceberen per fer-los servir de plaça de captació. Un 
estudi particular de cada un podrà aclarir aquesta qüestió. Sobre el mapa, la disposició dels aljubs forma una corona al voltant de la zona central de la Mola i deixant entre ells i els espadats costaners una distància semblant en cada cas. Aquesta distància apareix actualment $i$ en la fotografia de 1956 ocupada per bosc, mentre que cap al centre de la Mola s'estenen els camps de conreu. S'ha de tenir en compte que la dita imatge correspon al moment de màxima expansió agrícola experimentat a Formentera, amb 2.671 persones a tota l'illa dedicades en bona part al sector primari. La població específica de la parròquia del Pilar de la Mola, que inclou la part de l'istme anomenada les Clotades, ha anat creixent en època contemporània i, així, el 1800 eren 272 persones i 461 el 1860 (Cirer, 1986, p. 137). Aquestes xifres de població implicaven l'existència física, material de seixanta-cinc cases a la Mola més vuit a baix, a les Clotades, una zona del pla incorporada a la dita parròquia. Naturalment, els vint-i-cinc jaciments andalusins detectats en les prospeccions estan lluny d'aquestes xifres $i$ això suposant que tots ells fossin llocs de residència i tenint en compte la diferent composició de les famílies contemporànies cristianes respecte de les andalusines.

La posició descrita dels aljubs i la seva relació amb els jaciments andalusins localitzats a la zona pot estar indicant una jerarquia d'usos del sòl de l'indret i un calendari. El bosc exterior a la corona que descriuen els aljubs pogué usar-se com a lloc de pastura estacional. A la vegada, tal disposició descriu un espai interior, planer i de terres relativament fondes, en el qual s'hauria practicat agricultura "de secà". És a dir, una activitat de reproducció de plantes en llocs habilitats a l'efecte el regatge de les quals depenia únicament de la pluja (Retamero, 2011, p.32). Aquesta zona de la Mola era on s'havia de situar la reserva que Montgrí fa en el document de 1246 d'un espai que poguessin llaurar tres parells de bous. No es pot descartar una "transhumància local" des de la part baixa de Formentera cap a la Mola. L'estudi dels pous d'abeurada i els aljubs de la part baixa de l'illa està encara per fer. Les mencions ja al·ludides a una zona d'hort ubicada a la part baixa immediata a la Mola, coneguda com les Clotades, han de fer referència a horts creats a partir de l'aigua aflorada de pous per mitjà de sénies; com s'ha dit, l'any $2009^{7}$ s'hi inventariaren set sénies tradicionals. Els bous capturats pels pisans el 1114 podrien haver-ne accionat alguna de les que hi devia haver en aquell temps ja que no hi ha rastre d'altre tipus d'infraestructura de reguiu. El fruit d'aquells horts devia completar el ventall local de possibilitats de supervivència, juntament amb la pesca i la recol·lecció de mol·luscs (Ramon i Colomar, 2010, p.158). La presència, relativament abundosa de ceràmica no produïda a l'illa, mostren que aquella supervivència s'obtenia incorporant la celebració d'intercanvis que probablement sobretot el producte del bestiar formatge, llana i els animals mateixos— feia factibles (Retamero, 2011, p.44).

\section{Conclusions}

L'any 1995 Miquel Barceló va formular el problema que suscitava la detecció arqueològica de l'existència, en el terme de Felanitx, Mallorca, d'assentaments andalusins "no regits per la lògica de l'aigua" que basaven la seva reproducció en "opcions socials clarament ramaderes" (Barceló y Kirchner, 1995, p.11). D'aleshores ençà s'han documentat a altres indrets assentaments allunyats d'aqüífers o vora petits aqüífers insuficients per crear una superfície d'hort capaç d'alimentar de manera sostinguda el grup humà establert a la zona. Aquells grups havien de tenir en la ramaderia una activitat preferent (Barceló, 1997, p. 32). La proposta de Barceló és que els assentaments principals, tots ells hidràulics, generaren una "dispersió activa d'assentaments en el seu entorn" (Barceló y Kirchner, 1995, p.11). Els pagesos d'aquests altres llocs bé crearen espais hidràulics a partir de surgències de cabal minso si n'hi havia, bé es decantaren més exclusivament cap a la ramaderia o produïren un

7 Catàleg del Patrimoni cultural de Formentera, coordinat per A. Ferrer Abárzuza. 
sistema de combinació d'ambdues solucions (Barceló, 1997, p. 32).

Des d'aquesta perspectiva, el cas de l'illa de Formentera és comparable a la zona mallorquina on Barceló i Kirchner centraren el seu estudi. Els assentaments principals, certament hidràulics, ara ben coneguts, se situaren a l'illa d'Eivissa (Barceló, 1997, p. 21). Els clans que els crearen a partir del 902, haurien relegat a zones marginals, això és sense aqǘfers o amb surgències de cabal reduït a altres grups. Aquest desplaçament cap a les vores de la zona on es construïren els principals espais irrigats significà que aquests grups hagueren de "definir un horitzó de subsistència al marge de l'opció hidràulica" (Barceló y Kirchner, 1995, p.12). L'illa de Formentera, com els extrems de llevant i, especialment, de ponent d'Eivissa, eren llocs on l'agricultura irrigada només podia ser una opció complementària, mentre que a Eivissa la ramaderia s'hauria de mostrar, com crec que ja es mostra clarament a Formentera, com l'activitat principal d'aquells grups.

Amb aqüífers minsos -tot i que no del tot absents-, els habitants de Formentera es dedicaren efectivament a la ramaderia. Els documents feudals ens han transmès els noms de dues alqueries, la d'Alchanito, o Alchavito, i la dels Arenals. Hi ha raons per suposar que tots dos noms es refereixen a la mateixa alqueria. No sabem si n'hi havia més però no tenim cap indici per suposar-ho ja que, coneguda l'extensió de les alqueries de Yâbisa (Eivissa), no hauria d'estranyar que una sola alqueria abastés tot el territori de l'illa. El fet que el gruix dels documents del segle XIII ja comentats tinguin relació amb la zona de la Mola i amb la que actualment s'anomena de les Clotades pot estar assenyalant clarament l'indret més poblat de Formentera en època andalusí, o bé la porció de l'illa que més interès despertà entre els feudals per les característiques d'allò que els andalusins hi havien fet. Els resultats de la prospecció de tota l'illa realitzada el 1988 confirma, arran de la situació dels jaciments andalusins, la primera opció i, de retruc, que els feudals s'adaptaren a allò que havien conquerit (Figura 8).

R. Soto, va proposar ja fa estona si a major activitat ramadera en una regió s'havia de deduir una menor densitat de població. La situació extrema d'aquesta equació seria la d'absència de poblament humà estable però mantenint-hi un alt nombre d'animals (Soto, 1992, p. 15). En aquest cas es frega el límit de la ramaderia, ja que el mateix Soto fa esment de bestiar salvatgí. Línies amunt hem tractat de l'ús de corral que alguns eivissencs feien de l'illa de Formentera i també que en ocasions aquell bestiar, tornat salvatge, s'havia de caçar per cobrar-lo. Hi ha, sense sortir de l'arxipèlag, altres exemples d'això mateix. En general, en època recent sembla que tots els illots eren convertits en reservoris de carn. La proposta de R. Soto troba un element favorable més si s'observa la distribució dels jaciments de d'Eivissa (Kirchner, 2002b) i de Formentera (Figura 1). Els buits existents a Eivissa, com s'ha dit, estan per estudiar, Pel que fa a Formentera, la proposta, raonada en aquestes pàgines, que els aljubs de la Mola són l'evidència d'una ramaderia andalusí permet, crec, sortir del raonament circular que atribueix la dedicació ramadera als llocs on la prospecció detecta baixes densitats de poblament en aquell període.

La qüestió, pel que fa a Formentera, està en el seu estadi inicial. El treball de camp està quasi tot per fer. Falta encara una descripció detallada de les formes construïdes que haurien format part d'aquella opció ramadera dels habitants andalusins de Faramantira. Aquesta tasca haurà de permetre la comparació amb evidències semblants, discriminar cronologies i, després, calcular volums. 


\section{Agraïments}

La recerca de la qual aquest article és una presentació s'inscriu en el projecte del Grup Consolidat de Recerca Arqueologia Agrària de l'Edat Mitjana, Departament de Ciències de l'Antiguitat i de l'Edat Mitjana, Universitat Autònoma de Barcelona; investigadora principal, Helena Kirchner. Vull expressar el meu agraïment a Sívia Tur.

\section{Referències}

Aguiló, E. (1910-1911): Actes de venta o de modificació de domini otorgats per primers grans porcioners de l'illa, Bolleti de la Societat Arqueológica Luliana, XIII, pp. 265-266.

Barceló, M. (1984), Alguns problemes d'història agrària mallorquina suggerits pel text d'alZuhrî, en Barceló, M. Sobre Mayûrqa, "Quaderns de Ca la Gran Cristiana", Palma, pp. 35-53. També Barceló, M. (1974), Recerques, 8, pp. 27-49.

Barceló, M. et alii (1988): Arqueología medieval. En las afueras del «medievalismo», Barcelona, Crítica.

Barceló, M.; Kirchner, H., (1995): Terra de Falanis. Felanitx quan no ho era. Assentaments andalusins al territori de Felanitx, Palma, Universitat de les Illes Balears, Ajuntament de Felanitx.

Barceló, M. Ed. (1997): El curs de les aigües. Treballs sobre els pagesos de Yabisa (290-633H / $902-$ $1235 d C$ ), "Quaderns d'arqueologia pitiüsa", 3, Eivissa, Consell Insular d'Eivissa i Formentera.

Batet Company, C. (2004): L'aigua conquerida. Hidraulisme feudal en terres de conquesta, València, Publicacions de la Universitat de València, Universitat Autònoma de Barcelona.

Bayart, P. (2004), La Mola, Enciclopèdia d'Eivissa i Formentera, 8: 264-274.

Bazzana, A. (1992): Maisons d'al-Andalus. Habitat médiéval et structures du peuplement dans l'Espagne orientale, Madrid, Casa de Velázquez, 2 vol.

Cara Barrionuevo, L.; Rodríguez López, J.M. (1989): El ámbito económico del pastoralismo andalusí. Grandes aljibes ganaderos en la provincia de Almería, El agua en zonas áridas: arqueología e historia. I Coloquio de Historia y Medio Físico, Almería, Instituto de Estudios Almerienses, 2 vols, 2: 633-649.

Cara Barrionuevo, L.; Rodríguez López, J.M. (1989b): El pastoralismo en al-Andalus. Aproximación arqueológica en el sureste peninsular, Revista de Arqueología, 96: 40-48.

Cirer Costa, J.C. (1986): 1790-1920. Demografia i comerç d'Eivissa i Formentera. 130 anys d'una economia viva, Eivissa, Institut d'Estudis Eivissencs.

Colomar Roig, J.Ll. (2006) Geografia física, en V. Ferrer Mayans, Ed., Formentera, Eivissa, Consell Insular d'Eivissa i Formentera, Obra Cultural Balear de Formentera, pp. 60-69.

Díes Cusí, E; González Villaescusa, R. (1991): Evolución de la ocupación del suelo en Formentera: épocas púnicas y romana, Cuadernos de Prehistoria y Arqueología Castellonsenses, 15: 335-374.

Escandell Bonet, B. (1994): Ibiza y Formentera en la Corona de Aragón (siglos XIII-XVIII), Palma, Edicions El Tall.

Ferrer Abárzuza, A. (2008) L'Eivissa de Jaume I, Eivissa, Govern de les Illes Balears, Consell d'Eivissa.

Guasch Ribas, X. (2006): Geologia, en V. Ferrer Mayans, Ed., Formentera, Eivissa, Consell Insular d'Eivissa i Formentera, Obra Cultural Balear de Formentera, pp. 16-28.

Jordán, J. (1712): Historia de la provincia de la Corona de Aragón de la Sagrada Orden de los Ermitaños de nuestro gran Padre San Augustín. Compuesta de quatro reynos, Valencia, Aragón, Cataluña y las islas 
de Mallorca y Menorca, vol. 2, València, Impremta de Antoni Bordazar.

Juan Castelló, J. Ed. (1996): De Bello Maioricano. Libri Octo. La Guerra de Mallorca en ocho libros, Lorenzo Veronés-Laurentii Veronensis, Barcelona, Editorial Bosch.

Juan Ferrer, M. (2006): Economia, en V. Ferrer Mayans, Ed., Formentera, Eivissa, Consell Insular d'Eivissa i Formentera, Obra Cultural Balear de Formentera, pp. 80-95.

Kirchner, H. (2002): La ceràmica de Yâbisa. Catàleg i estudi dels fons del Musen Arqueològic d'Eivissa i Formentera, "Treballs del Museu Arqueològic d'Eivissa i Formentera", 49, Eivissa.

Kirchner, H. (2002b): El mapa de los asentamientos andalusíes de Ibiza, a C. Trillo (Ed.) IIIas Jornadas de arqueología medieval: Asentamientos rurales y territorio en el mundo mediterráneo en época medieval. Berja 2-5 nov. 2000, Granada, pp. 120-186.

Macabich, I. (1967): Historia de Ibiza, 4 vols, Palma, Ediciones Daédalus.

Mañá de Angulo, J.M. (1956): Notas arqueológicas sobre Formentera, Memorias de los Museos Arqueológicos Provinciales, pp. XIII-XIV.

Marí Cardona, J. (1976): La conquista catalana de 1235, Eivissa, Patronato José María Quadrado, Institut d'Estudis Eivissencs.

Marí Cardona, J. (1983): Formentera, col·lecció "Illes Pitiüses” III, Eivissa, Institut d'Estudis Eivissencs.

Marí Cardona, J. (1992): Els camins i les imatges de l'arxiduc abir $i$ avui, Eivissa, Institut d'Estudis Eivissencs.

Marí Cardona J. (1994): Formentera. Documentació $i$ paisatges, Eivissa, Institut d'Estudis Eivissencs.

Ramon, J.; Colomar, M. (2010): El recinte de l'edat del bronze i l'habitatge andalusí de sa Cala (La Mola, Formentera), Quaderns de Prehistòria i Arqueologia de Castelló, 28: 139-166.

Retamero Serralvo, F. (2011): Pautes per a l'estudi dels conreus de secà a Alandalús, Arqueologia Medieval, IV, “Els espais de secà”, pp. 31-49.

Ribes Marí, E. (1996) Carnatge, es, Enciclopèdia d'Eivissa i Formentera, Eivissa, Consell Insular d'Eivissa i Formentera, vol. 2: 362.

Ruíz Molina, L.; Azorín Cantó, M., (1989): Aljibes cimbrados en el área de Yecla (Murcia). Notas para el estudio de la ganadería trashumante en el NE de la región de Murcia. Siglos XII al XIX, El agua en zonas áridas: arqueología e historia. I Coloquio de Historia y Medio Físico, Almería, Instituto de Estudios Almerienses, 2 vols, 2: 609-630.

Sánchez Sedano, M.P. (1988): Arquitectura musulmana en la provincia de Almería, Almería, Diputación Provincial de Almería.

Serra Rodríguez, J.J. (2006): Inventari del patrimoni bidràulic de les Pitiüses. Inventari dels pous del municipi d'Eivissa $i$ dels pous, aljubs $i$ cisternes de Formentera, Eivissa, Consell Insular d'Eivissa i Formentera, p. 8.

Soto Company, R. (1992): Soto Company, R. (1992): Ovelles, vaques, porcs i eclesiàstics (Algunes consideracions sobre la ramaderia balear a l'Edat Mitjana, segles XI-XIV, Estudis d'Història Econòmica, 1, 1: 13-29.

Sureda i Jubany, M. (2010): La memòria escrita d'un clergue il·lustre. Documents de Guillem de Montgrí, Miscel-lània en honor de Josep M. Marquès, Publicacions de l'Abadia de Montserrat, pp. 197-211.

Torelli da Bologna, L. (1675): Secoli Agostiniani Secoli Agostiniani overo Historia generale del sacro ordine eremitano del gran dottore di Santa Chiesa S. Aurelio Agostino vescovo d'Hippona, vol. IV, 
Bolonya, Edició en línia a http://www.cassiciaco.it.

Torres, J.M. (1988): La zooarqueología, a M. Barceló (Ed.): Arqueología medieval. En las afueras del «medievalismo», Barcelona, Crítica, pp. 134-164.

Torres Peters, F.X. (2004): L'ocàs del monestir de Santa Maria de Formentera, Estudis Baleàrics. Homenatge a Marià Villangómez i Joan Marí Cardona, 73-74: 101-112.

Torres Peters, F.X. (2005): Nous documents envers l'antic monestir de Santa Maria de la Mola i la història medieval de Formentera, Eivissa, 42-43: 30-41.

Torres Peters, F.X. (2007): Senyors de Formentera a la baixa edat mitjana, Eivissa, 46: 9-16.

Torres Peters, F.X. (2011): Santa Maria de Formentera, monestir de, Enciclopèdia d'Eivissa $i$ Formentera, Eivissa, Consell Insular d'Eivissa i Formentera, vol. 11, pp. 168-169.

Torres Peters, F.X. (2014): El monestir de Santa Maria de la Mola, Formentera. Jornades d'Estudis Locals Joan Mari Cardona (12-16 de març de 2012), pp. 7-21.

Torres Peters, F.X. (en preparació) Transcripció del procés medieval núm. 1 de l'Arxiu Diocesà de Girona.

Vilà Valentí, J. (1985): Formentera. Estudi de Geografia humana, Ajuntament de Formentera.

Wickham, C. (1983): Pastoralism and underdevelopment in the Early Middle Ages, Settimane di studio del Centro Italiano di Studi sull'Alto Medioevo, vol. 1, pp. 401-455. 